\title{
Case Fatality Rate of COVID-19: Meta-Analysis Approach
}

\author{
Amir Almasi-Hashiani, PhD'; Amin Doosti-Irani, PhD²; Mohammad Ali Mansournia, MD, PhD $^{3^{*}}$ \\ ${ }^{1}$ Department of Epidemiology, School of Health, Arak University of Medical Sciences, Arak, Iran \\ ${ }^{2}$ Department of Epidemiology, School of Public Health and Research Center for Health Sciences, Hamadan University of Medical Sciences, \\ Hamadan, Iran \\ ${ }^{3}$ Department of Epidemiology and Biostatistics, School of Public Health, Tehran University of Medical Sciences, Tehran, Iran
}

\section{Dear Editor,}

A novel coronavirus (coronavirus disease 2019) that was named COVID-19 emerged in Wuhan, China, in December 2019 $9^{1-3}$ and is now rapidly increasing worldwide. According to the World Health Organization (WHO), the number of confirmed cases increased to more than 4500000 cases with 307000 deaths until May 18, 2020. ${ }^{4}$ COVID-19 has a spectrum of severity as mild, severe and critical and the disease outcome depends on its severity.

During a potentially fatal disease epidemic, one of the main indices to show the disease severity is case fatality rate (CFR) (the fraction of diagnosed cases who die from the disease). ${ }^{5}$ In a report from China, the overall CFR for COVID-19 was estimated at $2.3 \%$ (14.8\% in patients aged $\geq 80$ years, $8.0 \%$ in those aged $70-79$ years and $49.0 \%$ in critical cases). ${ }^{3}$ In other similar studies, the CFR has been calculated and reported that varies in different countries ${ }^{6-8}$ with the highest rates in the European countries.

Since there is no consensus on the value of CFR and knowing this index is important in the disease modeling and planning, in this study, we have used random-effects meta-analysis approach to estimate CFR.

The required data regarding COVID-19 was extracted on April 7, 2020 from the Worldometer webpage (https:// www.worldometers.info/coronavirus/). The CFR for each country was calculated by dividing the number of total deaths by the total confirmed cases; the values obtained for all countries were pooled using the random-effects metaanalysis approach to estimate the CFR by WHO regions, on the basis of the number of COVID-19 tests, percent of population aged 65 years and above, and the prevalence of diabetes mellitus (DM). Statistical heterogeneity was explored using $\chi^{2}$ test and quantified by $\mathrm{I}^{2}$ statistic. The data of age distribution (available from: https://data. worldbank.org/indicator/sp.pop.65up.to.zs) and DM prevalence (available from: https://data.worldbank.org/
indicator/SH.STA.DIAB.ZS?view=chart) was extracted from World Bank data. Analyses were done using Stata software version 13 (Stata Corp, College Station, TX).

As shown in Table 1, the overall estimated COVID-19 CFR is 3.3\% (95\% CI: 2.6-3.9). As for different WHO regions, the highest CFR pertained to AFRO $(5.1 \%$, 95\% CI: 1.1-9.1), followed by EURO (3.5\%, 95\% CI: 2.2-4.7), SEARO $(3.4 \%, 95 \%$ CI: $1.5-5.3)$, PAHO (3.3\%, 95\% CI: 2.6-4.0), EMRO (2.9\%, 95\% CI: 0.9$5.0)$ and WPRO $(1.8 \%, 95 \% \mathrm{CI}: 0.5-3.0)$. Since there is substantial heterogeneity between different countries in terms of CFR in WHO regions, merging them would face some limitations; therefore, we performed some subgroup analysis based on the number of COVID-19 tests per million, the percentage of population aged 65 years and above and DM prevalence. The results showed that the higher the number of COVID-19 tests per million, the lower the estimated CFR: the CFR ranged from 4\% (95\% CI: 3.1-4.8) in countries with less than 1,000 tests per million to $1.9 \%$ (95\% CI: $0.2-3.5)$ in countries with more than 10,000 tests. The results also showed that CFR was higher in countries with higher percentages of population aged 65 years and above: in countries where more than $20 \%$ of people are over 65 years of age, the CFR is 3.8\% (95\% CI: $1.2-6.4$ ), while in countries with $10 \%$ or less, the CFR is 3.4 (95\% CI: 2.6-4.3). In terms of DM prevalence, countries with higher DM prevalence showed a lower CFR (2.1\%, 95\% CI: 1.5-2.6): in countries with a prevalence of diabetes of less than $5 \%$, the CFR was estimated at 3.7\% (95\% CI: 1.8-5.5).

In addition to subgroup analysis, meta-regression was conducted to explain the heterogeneity. The meta-regression results showed that there is an inverse association between the number of COVID-19 tests per million and CFR $(P=0.001)$; also, being in the WPRO region is related with a lower CFR $(P=0.004)$. In addition

*Corresponding Author: Mohammad Ali Mansournia, MD, PhD; Department of Epidemiology and Biostatistics, School of Public Health, Tehran University of Medical Sciences, Tehran, 14155-6446, Iran. Tel: +98-88989127; Fax: +98-88989127; Email: mansournia_ma@yahoo.com 
Table 1. Estimated CFR of COVID-19 by WHO Regions, COVID-19 Tests Per Million, Prevalence of DM and the Percent of Population Aged 65 Years and Above

\begin{tabular}{|c|c|c|c|c|c|c|}
\hline Subgroups & & Number of Countries & CFR & $95 \% \mathrm{Cl}$ & Weight (\%) & $I^{2}$ Statistic \\
\hline \multirow{6}{*}{ WHO regions } & WPRO & 9 & 1.8 & $0.5-3.0$ & 11.39 & $99.4 \%$ \\
\hline & EMRO & 10 & 2.9 & $0.9-5.0$ & 12.37 & $99.6 \%$ \\
\hline & PAHO & 11 & 3.3 & $2.6-4.0$ & 13.81 & $98.0 \%$ \\
\hline & SEARO & 4 & 3.4 & $1.5-5.3$ & 5.02 & $98.2 \%$ \\
\hline & EURO & 42 & 3.5 & $2.2-4.7$ & 52.51 & $99.9 \%$ \\
\hline & AFRO & 4 & 5.1 & $1.1-9.1$ & 4.89 & $98.6 \%$ \\
\hline \multirow{4}{*}{ COVID-19 test per M } & $<1000$ per $M$ & 21 & 4.0 & $3.1-4.8$ & 26.08 & $97.1 \%$ \\
\hline & $1000-5000$ per $M$ & 21 & 3.7 & $2.1-5.3$ & 26.06 & $99.7 \%$ \\
\hline & 5000-10000 per M & 13 & 3.6 & $1.9-5.4$ & 16.45 & $99.9 \%$ \\
\hline & $>10000$ per $M$ & 18 & 1.9 & $0.2-3.5$ & 22.76 & $99.9 \%$ \\
\hline \multirow{3}{*}{$\begin{array}{l}\text { The \% of population aged } \\
65 \text { years and above }\end{array}$} & $1 \%-10 \%$ & 29 & 3.4 & $2.6-4.3$ & 36.06 & $99.0 \%$ \\
\hline & $11 \%-19 \%$ & 35 & 2.9 & $2.0-3.8$ & 43.97 & $99.8 \%$ \\
\hline & $20 \%$ or more & 15 & 3.8 & $1.2-6.4$ & 18.79 & $99.9 \%$ \\
\hline \multirow{3}{*}{ DM prevalence (\%) } & $1 \%-5 \%$ & 26 & 3.7 & $1.8-5.5$ & 32.72 & $99.8 \%$ \\
\hline & $6 \%-10 \%$ & 38 & 3.4 & $2.4-4.4$ & 47.17 & $99.7 \%$ \\
\hline & $10 \%$ or more & 16 & 2.1 & $1.5-2.6$ & 20.11 & $99.1 \%$ \\
\hline Overall & & 80 & 3.3 & $2.6-3.9$ & 100.0 & $99.8 \%$ \\
\hline
\end{tabular}

CFR, case fatality rate; WHO, World Health Organization; WPRO, Western Pacific Region; EMRO, Eastern Mediterranean Region; PAHO, Region of the Americas; SEARO, South-East Asia Region; EURO, European Region; AFRO, African Region; M, million; DM, diabetes mellitus.

to the mentioned results, Spearman correlation showed a significant negative correlation between the number of COVID-19 tests per million and CFR (Spearman's rho $=$ -0.43, $P=0.001)$.

The overall CFR was estimated to be 3.3 in the present study. Compared to the initial reports from China, the estimated CFR in our analysis is nearly 1.5 times the value reported by Wu $\mathrm{Z}$ and McGoogan $\mathrm{JM}^{3}$ which was 2.3\% (1023 deaths among 44672 cases) and also nearly 2.5 times the value reported by Wu et al. ${ }^{9}$ who reported the overall symptomatic CFR as $1.4 \%(0.9-2.1 \%)$ in their study. However, in recent studies from China, the overall CFR was estimated at $3.06 \%(95 \%$ CI $2.02-4.59){ }^{10}$ which is almost similar to the results of our study.

Despite the controversy surrounding COVID-19 CFR, it is clear that CFR of COVID-19 is noticeably lower than that CFRs of SARS (9.5\%) and MERS (34.4\%) but higher than seasonal influenza $(0.1 \%) .{ }^{11}$

The results suggested that the higher the number of COVID-19 tests per million, the lower the estimated CFR. The number of COVID-19 tests per million performed in each country can be probably considered as an appropriate proxy for the level of health care services such as the numbers of critical care beds, leading to a lower CFR. However, this can be explained by the fact that countries with more tests tend to find more mild patients with less fatality.

Comparison of different WHO regions shows that the highest CFR pertains to African countries, possibly due to the fact that preventive services, followed by health care and facilities in these countries, are weaker, leading to higher disease fatality. The surprising thing is that after African countries, European countries have the highest CFR. These countries, many of which are tourist destinations (such as Italy, Spain, Germany, etc), have more passengers than epicenter countries, and this is likely to lead to the rapid growth of the disease and the overcrowding of patients in hospitals, finally leading to higher CFR.

Previous studies have shown that CFR is higher among the elderly than young people, ${ }^{3,10}$ and it is higher among people with a past medical history. ${ }^{7}$ However, the results of our analysis show that although the mortality rate is higher in older countries $(3.8 \%)$, the CFR is not higher $(2.1 \%)$ in countries with a higher prevalence of diabetes (10\% or more).

In summary, the CFR is 3.3, being the highest in AFRO and the lowest in WPRO. Also, it is smaller in countries with more COVID-19 tests, and greater in older countries. It is important to note that given that a large proportion of patients are mild/asymptomatic and unidentified, it is more likely that the estimated CFR is an overestimation.

\section{Authors' Contribution}

AAH and MAM: designed the study and did the literature search. AAH, MAM and ADI: were responsible for data collection. AAH, MAM and ADI: analyzed the data. All authors drafted and revised the report.

\section{Conflict of Interest Disclosures}

All authors declared no conflict of interest.

Ethical Statement

Not applicable. 


\section{References}

1. Huang C, Wang Y, Li X, Ren L, Zhao J, Hu Y, et al. Clinical features of patients infected with 2019 novel coronavirus in Wuhan, China. Lancet. 2020;395(10223):497-506. doi: 10.1016/S0140-6736(20)30183-5.

2. Sun K, Chen J, Viboud C. Early epidemiological analysis of the coronavirus disease 2019 outbreak based on crowdsourced data: a population-level observational study. Lancet Digit Health. 2020;2(4):e201-e8. doi: 10.1016/S25897500(20)30026-1.

3. Wu Z, McGoogan JM. Characteristics of and Important Lessons From the Coronavirus Disease 2019 (COVID-19) Outbreak in China: Summary of a Report of 72314 Cases From the Chinese Center for Disease Control and Prevention. JAMA. 2020;323(13):1239-42. doi: 10.1001/jama.2020.2648.

4. World Health Organization. Coronavirus disease 2019 (COVID-19) Situation Report - 1182020 [18 May 2020]. Available from: https://www.who.int/docs/default-source/ coronaviruse/situation-reports/20200517-covid-19sitrep-118. pdf?sfvrsn=21 c0dafe 6 .

5. Ghani AC, Donnelly CA, Cox DR, Griffin JT, Fraser C, Lam $\mathrm{TH}$, et al. Methods for Estimating the Case Fatality Ratio for a Novel, Emerging Infectious Disease. Am J Epidemiol.
2005;162(5):479-86. doi: 10.1093/aje/kwi230

6. Spychalski P, Błażyńska-Spychalska A, Kobiela J. Estimating case fatality rates of COVID-19. Lancet Infect Dis. 2020;20(7):774-5. doi: 10.1016/S1473-3099(20)30246-2 .

7. Onder G, Rezza G, Brusaferro S. Case-fatality rate and characteristics of patients dying in relation to COVID-19 in Italy. Jama. 2020;323(18):1775-6. doi:10.1001/jama.2020.4683.

8. Khafaie MA, Rahim F. Cross-country comparison of case fatality rates of COVID-19/SARS-COV-2. Osong Public Health Res Perspect. 2020;11(2):74. doi: 10.24171/j.phrp.2020.11.2.03.

9. Wu JT, Leung K, Bushman M, Kishore N, Niehus R, de Salazar PM, et al. Estimating clinical severity of COVID-19 from the transmission dynamics in Wuhan, China. Nat Med. 2020;26(4):506-10. doi: 10.1038/s41591-020-0822-7.

10. Yang $Y$, Lu $Q$, Liu $M$, Wang $Y$, Zhang $A$, Jalali $N$, et al. Epidemiological and clinical features of the 2019 novel coronavirus outbreak in China. medRxiv. 2020. doi: 10.1101/2020.02.10.20021675.

11. Rajgor DD, Lee MH, Archuleta S, Bagdasarian N, Quek SC. The many estimates of the COVID-19 case fatality rate. Lancet Infect Dis. 2020;20(7):776-7. doi: 10.1016/S14733099(20)30244-9.

Received: May 27, 2020, Accepted: July 1, 2020, ePublished: September 1, 2020

Cite this article as: Almasi-Hashiani A, Doosti-Irani A, Mansournia MA. Case fatality rate of COVID-19: meta-analysis approach. Arch Iran Med. 2020;23(9):644646. doi: 10.34172/aim.2020.78.

(c) (1) (c) 2020 The Author(s). This is an open-access article distributed under the terms of the Creative Commons Attribution License (http://creativecommons org/licenses/by/4.0), which permits unrestricted use, distribution, and reproduction in any medium, provided the original work is properly cited. 